\title{
EFFECT OF LATERAL STIFFNESS OF SECONDARY SUSPENSIONS ON HEAVY-HAUL LOCOMOTIVES STABILITY DURING BRAKING BASED ON SIMULATION AND EXPERIMENT
}

\author{
Lirong GUO, Kaiyun WANG*, Zaigang CHEN, Zhiyong SHI, Kaikai LV, Rui ZHANG \\ State Key Laboratory of Traction Power, Southwest Jiaotong University, Chengdu, China
}

Received 23 September 2016; revised 11 December 2016, 18 January 2017; accepted 28 January 2017

\begin{abstract}
This paper aimed to investigate the effect of the lateral stiffness of secondary suspensions on the stability capacity and running safety of heavy-haul locomotives during braking based on the dynamic model and the field braking tests. The dynamic model of heavy-haul locomotives included two double-unit locomotives and five coupler systems. Simulation results indicate that the increasing of the lateral stiffness of secondary suspensions can improve the stability capacity and running safety of heavy-haul locomotives. Then, the field braking experiments were conducted to validate the dynamic model. Comparing the experiment results of different locomotives, the coupler and carbody yaw angles are respectively decreased by 31.8 and $29.5 \%$, which is consistent with the simulation results. It is worthy to be noted that lateral vibration behaviour of the carbody increases with the increasing of the lateral stiffness of secondary suspensions. For the improved locomotive, the main frequency of lateral acceleration is $1 \ldots 2 \mathrm{~Hz}$. However, the main frequency of lateral acceleration is $0.5 \ldots 1 \mathrm{~Hz}$ in the original locomotive tests. Moreover, the high-frequency vibration is increased, especially in $10 \ldots 12.5 \mathrm{~Hz}$. According to the simulation and experiment results, the reasonable lateral stiffness of secondary suspensions is $400 \mathrm{kN} / \mathrm{m}$ for the test locomotive.
\end{abstract}

Keywords: locomotive stability, coupler and draft gear system, braking, lateral stiffness, secondary suspensions, running safety.

\section{Introduction}

When the heavy-haul train is braking, the lateral components of the coupler compressive forces makes the heavy-haul locomotive yaw unstable and may lead to a derailment, particularly for the locomotive in the middle of heavy-haul train (Ma et al. 2012; Wu et al. 2014). The stability capacity of heavy-haul locomotives has a significant influence on the dynamic performance and running safety of heavy-haul trains, especially when the train is in emergency braking. As an example, the passing plates of heavy-haul locomotives were transformed and destroyed in the Chinese Daqin Railway because of the large yaw angle of locomotives during braking (Zhang et al. 2015). Derailments caused by locomotives instability may occur with the increasing of the train tonnage and running speed (Geike 2007; Wu et al. 2014; Guo et al. 2016). Scholars have conducted many studies on the longitudinal dynamics of heavy-haul trains, the wheel-rail dynamic vibration, the wagon connection model, the influence of the coupler stability on running safety of heavy-haul locomo- tives (Cole et al. 2012; Cole, Sun 2006; Wang et al. 2009, 2015, 2016a, 2016b; Belforte et al. 2008; Nasr, Mohammadi 2010; Simson, Cole 2008). However, these studies did not consider the heavy-haul locomotive stability, its effect on dynamic performance and running safety when the locomotive sustains a severe longitudinal compressive force.

According to the stability mechanism, the couplers of heavy-haul locomotives can be divided into two types, friction arc surface couplers and restoring bump stopper couplers. Ma et al. (2012), Xu et al. (2014) and Wu et al. (2012) developed dynamic models of these two kinds of couplers to analyse the structures and stabilizing mechanisms of them, and investigated the effect of these couplers on dynamic performance of heavy-haul locomotives during braking. Yao et al. (2013) conducted many studies on these coupler systems, including the geometric and mechanical characteristics of the bumpstop coupler, the stability mechanism of the arc surface coupler, and the

*Corresponding author. E-mail: kywang@swjtu.edu.cn 
critical factors to improve the coupler stability. Zhang et al. (2015) built an arc surface to arc surface contact friction element to study the coupler stability and investigated the influence of friction coefficient and other parameters on running safety of locomotives. These studies all proposed that the heavy-haul locomotive has a considerable effect on preventing coupler's lateral force and improving running safety of locomotive.

In this paper, the effect of the lateral stiffness of secondary suspensions on the stability capacity and running safety of heavy-haul locomotives was investigated by both the simulation model and the field braking experiment. The dynamic model of locomotives was developed to study the effect of the lateral stiffness of secondary suspensions. Then, the field braking experiments, using three double-unit locomotives, were conducted to validate the dynamic model and the conclusions of the simulation.

\section{Simulation model of locomotives}

Figure 1 illustrates the force analysis of the locomotive under the longitudinal compressive forces, where $F_{c 1,2}$ and $d_{c}$ are compressive forces caused by coupler and its arm length, respectively; $F_{s 1,2}$ and $d_{s}$ are the lateral forces provided by the locomotive and the distance of secondary suspensions, respectively. Due to the coupler deflection during braking, couplers lateral forces are generated and applied on the locomotive, which cause an overturning moment $F_{c 2} \cdot d_{c}$ to make locomotive yaw unstable. The restrictive forces provided by secondary suspensions will produce a stabilizing moment $\frac{\left(F_{s 1}+F_{s 2}\right) \cdot d_{s}}{2}$ to prevent the locomotive rotation. These restrictive forces are transferred to the bogie by the secondary and primary suspension systems, so an additional wheelset lateral force is increased. The larger yaw angle of locomotive will lead to a greater wheelset lateral force, which may lead to a derailment. Especially when the rigid contact between the carbody and the bogie occurs, the wheelset lateral force will increase to a very large value in a short time. Therefore, the lateral stiffness of secondary suspension systems plays an important role in improving heavy-haul locomotive stability during braking.

In order to verify the theoretical analysis, a dynamic model of heavy-haul locomotives has been built using the multi-body dynamics software SIMPACK (https:// www.3ds.com/products-services/simulia/products/simpack). The dynamic model includes two double-unit locomotives and one freight vehicle, which represented all the freight vehicles in the train and was modelled as a single mass with only one degree of freedom in the longitudinal direction. The train dynamic model was connected by $13 \mathrm{~A} / \mathrm{QKX} 100$ coupler and draft gear system, which is a typical kind of coupler system with friction arc surface and widely used in Chinese heavy-haul train. It could simulate the yaw behaviour and dynamic performance of heavy-haul locomotive during braking.

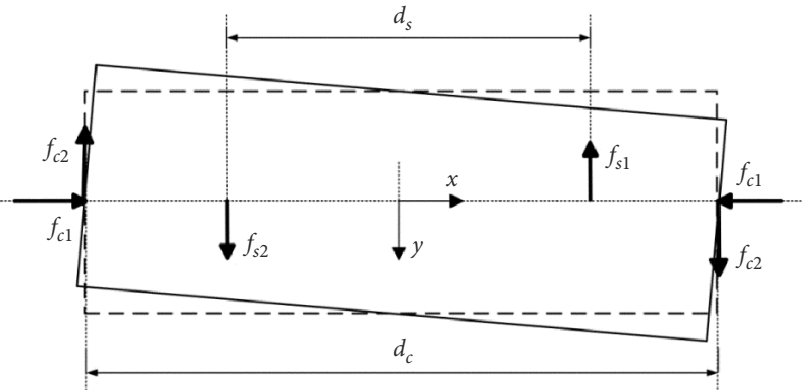

Figure 1. Force analysis of heavy-haul locomotive during braking

\subsection{Double-unit locomotive model}

One double-unit locomotive model includes two identical locomotives according to the test locomotive. Its bogie consists of motors, wheelsets, bogie frames, primary and secondary suspensions and attachments. The axle type in the model is Bo-Bo. There are 46 independent Degrees Of Freedoms (DOFs). In the dynamic model, each carbody has 6 DOFs, each bogie has 6 independent DOFs, each wheelset has 6 independent DOFs, and each motor has only one DOF, as listed in Table 1.

Table 1. Independent DOFs of single locomotive dynamic model

\begin{tabular}{|l|c|c|c|c|c|c|}
\hline \multirow{2}{*}{ Component } & \multicolumn{3}{|c|}{ Translation } & \multicolumn{3}{c|}{ Rotation } \\
\cline { 2 - 8 } & $X$-axis & $Y$-axis & $Z$-axis & $X$-axis & $Y$-axis & $Z$-axis \\
\hline Wheelset & $\sqrt{ }$ & $\sqrt{ }$ & $\sqrt{ }$ & $\sqrt{ }$ & $\sqrt{ }$ & $\sqrt{ }$ \\
\hline Bogie & $\sqrt{ }$ & $\sqrt{ }$ & $\sqrt{ }$ & $\sqrt{ }$ & $\sqrt{ }$ & $\sqrt{ }$ \\
\hline Car body & $\sqrt{ }$ & $\sqrt{ }$ & $\sqrt{ }$ & $\sqrt{ }$ & $\sqrt{ }$ & $\sqrt{ }$ \\
\hline Motor & - & - & - & - & $\sqrt{ }$ & - \\
\hline
\end{tabular}

The gauge distance is $1435 \mathrm{~mm}$ and the axle load is 25 t. All suspensions and nonlinear dampers are considered in the dynamic model. The primary suspension is fixed by a primary spring, a vertical damper and a journal box pull rod. One side of secondary suspensions includes 2 secondary springs, a vertical damper and a lateral damper. Besides, the secondary lateral stopper setting on the longitudinal center of the bogie is used to provide the stopper stiffness. One side of the motor hangs on the wheel axle. However, the other side is connected to the bogie frame through the hang rod, which is called as the axle-hung suspension method. The main parameters of the locomotives are listed in Table 2. Figure 2 shows the double-unit locomotive model. Additionally, the wheel tread and the rail profile are JM3 wear-type tread and $75 \mathrm{~kg} / \mathrm{m}$ rail, respectively.

\subsection{Coupler and draft gear system model}

The coupler and draft gear system model is established based on 13A/QKX100 coupler and draft gear system. As shown in Figure 3, the coupler system includes a 13A coupler, suspender, coupler pin with special geometric structure, front following plate, coupler yoke and QKX100 draft gear. 
Table 2. The main parameters of the locomotive model

\begin{tabular}{|l|c|c|}
\hline \multicolumn{1}{|c|}{ Item } & Value & $\mathrm{Unit}$ \\
\hline Axle load & 25000 & $\mathrm{~kg}$ \\
\hline Mass of carbody & 62600 & $\mathrm{~kg}$ \\
\hline Mass of bogie & 7840 & $\mathrm{~kg}$ \\
\hline Mass of wheelset & 5430 & $\mathrm{~kg}$ \\
\hline Gauge distance & 1435 & $\mathrm{~mm}$ \\
\hline Distance between two bogies & 10060 & $\mathrm{~mm}$ \\
\hline Radius of wheelset & 625 & $\mathrm{~mm}$ \\
\hline Distance of between two couplers & 18975 & $\mathrm{~mm}$ \\
\hline $\begin{array}{l}\text { Primary suspension stiffness in longitudinal } \\
\text { direction }\end{array}$ & 1442 & $\mathrm{kN} / \mathrm{m}$ \\
\hline $\begin{array}{l}\text { Primary suspension stiffness in lateral } \\
\text { direction }\end{array}$ & 1442 & $\mathrm{kN} / \mathrm{m}$ \\
\hline $\begin{array}{l}\text { Primary suspension stiffness in vertical } \\
\text { direction }\end{array}$ & 1569 & $\mathrm{kN} / \mathrm{m}$ \\
\hline $\begin{array}{l}\text { Primary suspension damping in vertical } \\
\text { direction }\end{array}$ & 25 & $\mathrm{kN} \cdot \mathrm{s} / \mathrm{m}$ \\
\hline $\begin{array}{l}\text { Secondary suspension stiffness in } \\
\text { longitudinal direction }\end{array}$ & 130 & $\mathrm{kN} / \mathrm{m}$ \\
\hline $\begin{array}{l}\text { Secondary suspension stiffness in lateral } \\
\text { direction }\end{array}$ & 130 & $\mathrm{kN} / \mathrm{m}$ \\
\hline $\begin{array}{l}\text { Secondary suspension stiffness in vertical } \\
\text { direction }\end{array}$ & 1073 & $\mathrm{kN} / \mathrm{m}$ \\
\hline $\begin{array}{l}\text { Secondary suspension damping in lateral } \\
\text { direction }\end{array}$ & 79 & $\mathrm{kN} \cdot \mathrm{s} / \mathrm{m}$ \\
\hline Free clearance of secondary lateral stop & 20 & $\mathrm{~mm}$ \\
\hline Elastic clearance of secondary lateral stop & 40 & $\mathrm{~mm}$ \\
\hline $\begin{array}{l}\text { Elastic stiffness of the secondary lateral } \\
\text { stopper }\end{array}$ & 1575 & $\mathrm{kN} / \mathrm{m}$ \\
\hline $\begin{array}{l}\text { Lateral deviation between the front } \\
\text { and the rear couplers }\end{array}$ & 8 & $\mathrm{~mm}$ \\
\hline Installation error of the draft gears & 5 \\
\hline
\end{tabular}

During braking, the friction arc surfaces between coupler tail and the front following plate can prevent the coupler from deflecting the track center-line. Besides, the special coupler pin and pin hole act as a rotation stopper, which can limit the coupler yaw angle in a certain range. It should be pointed that the QKX100 draft gear is always under compression (Zhang et al. 2015). Thus, the draft gear model has the identical pulling and compressing properties. The QKX100 draft gear has nonlinear hysteretic characteristics, which means that its loading process and unloading process are different, as shown in Figure 4. This characteristic is benefit to absorb vibration energy.

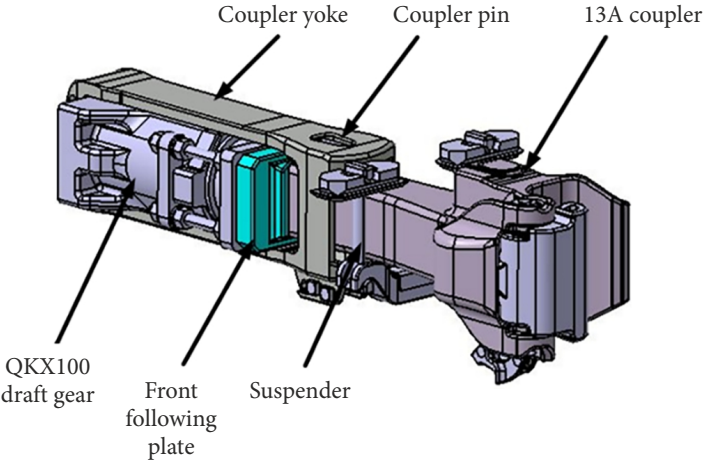

Figure 3. 13A/QKX100 coupler and draft gear system

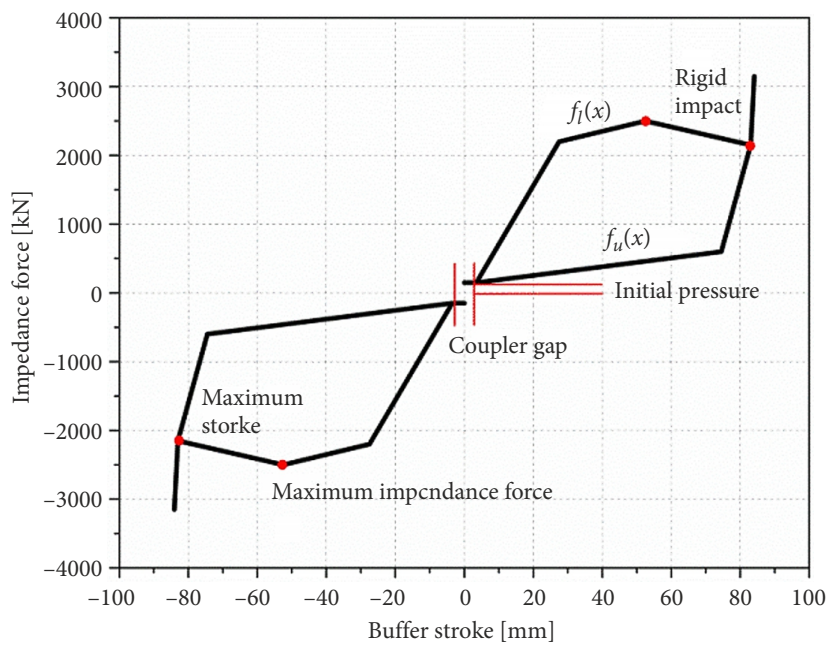

Figure 4. Nonlinear hysteretic characteristics of QKX100 draft gear

Therefore, the draft gear mathematical model can be defined as:

$F(x, \Delta v)= \begin{cases}f(x)+\left|f_{u}(x)-f_{l}(x)\right| \cdot \operatorname{sign}(\Delta v), & \Delta v \geq e v ; \\ f(x)+\frac{\Delta v}{e v} \cdot\left|f_{u}(x)-f_{l}(x)\right| \cdot \operatorname{sign}(\Delta v), & \Delta v<e v,\end{cases}$

where: $x$ is the draft gear stroke; $\Delta v$ is the rate of change of draft gear stroke; $e v$ is the switching rate of draft gear; $f_{u}(x)$ is the unloading function of the draft gear; $f_{l}(x)$ is the loading function of the draft gear. If the draft gear is in the loading state, $f(x)$ is equal to $f_{l}(x)$, otherwise, $f(x)$ is equal to $f_{u}(x)$.

The friction forces are determined by the friction coefficient and contact force between the arc surfaces. Figure 5 illustrates the contact model between the coupler tail and the front following plate, where point $\mathrm{O}$ is the center of

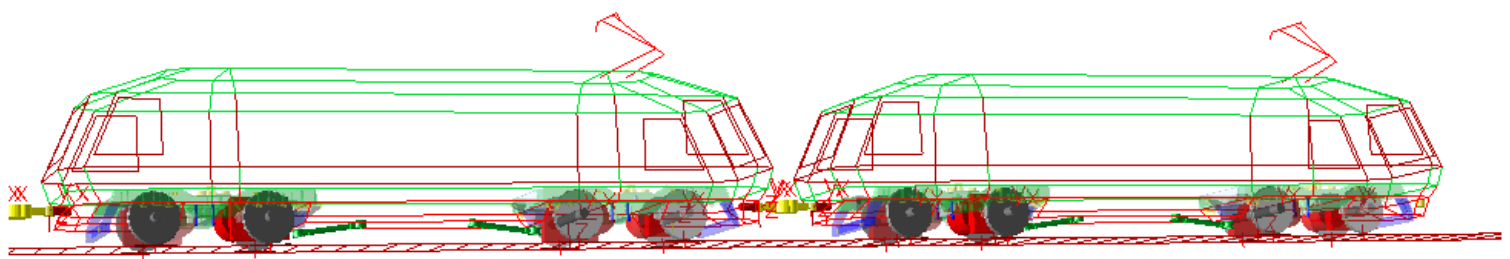

Figure 2. Double-unit locomotive model 
the front following plate arc surface; point $\mathrm{O}^{\prime}$ is the center of the coupler tail arc surface; point $C$ is the contact point between coupler tail and front following plate; $\theta$ is the coupler angle; $F_{f}$ is the friction force that prevents larger coupler angle. Establishing a coordinate system based on the point $\mathrm{O}$, the coupler angle and the coordinate of point $\mathrm{C}$ can be concluded:

$$
\begin{aligned}
& \theta=\arcsin \frac{x_{R}-x_{r}}{R-r} ; \\
& \left\{\begin{array}{l}
x_{C}=x_{R}-R \cdot \cos \theta ; \\
y_{C}=y_{R}+R \cdot \sin \theta
\end{array}\right.
\end{aligned}
$$

According to the Coulomb friction model, the mathematical expression of the friction force can be written as:

$$
F_{f}= \begin{cases}\frac{\left|v_{r}\right|}{v_{f}} \cdot F_{c} \cdot \mu \cdot \operatorname{sign}\left(v_{r}\right), & \left|v_{r}\right| \leq v_{f} ; \\ F_{c} \cdot \mu \cdot \operatorname{sign}\left(v_{r}\right), & \left|v_{r}\right|>v_{f},\end{cases}
$$

where: $F_{f}$ is the friction force of the friction pair; $F_{c}$ is the compressive force of the point $C ; \mu$ is the friction coefficient; $v_{r}$ is the relative velocity of the point $\mathrm{C}$; $v_{f}$ is the critical velocity of the static friction of the friction pair; $\operatorname{sign}\left(v_{r}\right)$ is the sign function of $v_{r}$.

Besides, the coupler pin and the pin hole act as a yaw angle stopper, which limits the maximum yaw angle of coupler. When the coupler reaches the maximum yaw angle, the coupler pin starts to work. According to its dynamic characteristic, it provides the restoring moment can be given as:

$$
M_{c}= \begin{cases}0, & |\theta|<\theta_{c m} ; \\ \left(\theta-\theta_{\text {free }} \cdot \operatorname{sign}(\theta)\right) \cdot l \cdot 10^{8}, & |\theta| \geq \theta_{c m},\end{cases}
$$

where: $M_{c}$ is the restoring moment provided by the coupler pin and the pin hole; $\theta$ is the yaw angle of the coupler; $\theta_{c m}$ is the maximum yaw angle of the coupler; $l$ is the longitudinal distance between the two stoppers of the

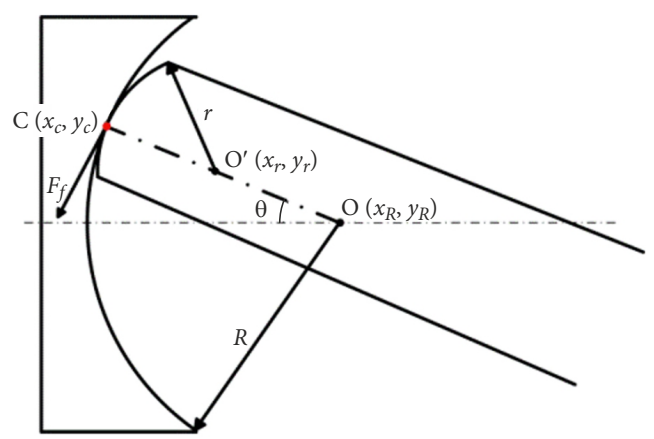

Figure 5. Mathematic model of the friction arc surface coupling couplers. In Chinese heavy-haul railway, $\theta_{c m}$ is commonly set as $9 \ldots 11^{\circ}$. In the coupler model, $\theta_{c m}$ was set as $10^{\circ}$.

Figure 6 shows the dynamic model of 13A/QKX100 coupler and draft gear system. It should be pointed that the position errors of coupler and draft gear systems were considered in the simulation model according to the field measurements, as listed in Table 2 (Wang et al. 2016a, 2016b).

\subsection{Calculation conditions}

To simulate the braking situation on the straight line, the running speed of the train model was set as a constant value $(60 \mathrm{~km} / \mathrm{h})$, and the braking force were applied on each wheelset of the front double-unit locomotive. Figure 7 shows the braking process in the model. It should be pointed that the freight vehicle is just a single mass with only longitudinal degree of freedom. American Federal Railroad Administration (FRA) Class 5 track irregularities were applied in the dynamic model because there are no real measured track irregularities for the test line (Yao et al. 2013, 2014; Zhai et al. 2015; Zhai 2020; Chen et al. 2017). In addition, the simulation model took the contact parameters of new wheel and rail profiles as input parameters. In the simulation, the time from the start braking to the maximum coupler force $(100 \mathrm{kN}$ per axle) was $10 \mathrm{~s}$, and its calculation step was $0.05 \mathrm{~s}$. The lateral stiffness of secondary suspension system was assumed to vary from 100 to $500 \mathrm{kN} / \mathrm{m}$.

\section{Analysis of the simulation results}

Figure 8 shows the carbody and coupler yaw angles under different lateral stiffness of secondary suspensions. It is clear that the yaw angles gradually decrease with the increasing of the lateral stiffness of secondary suspensions, which indicates that the stability capacity of heavy-haul

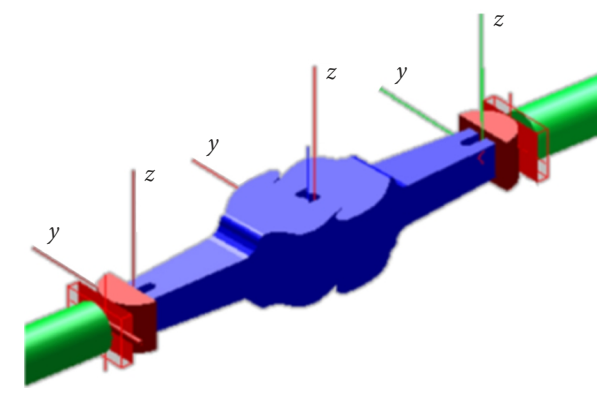

Figure 6. 13A/QKX100 coupler and draft gear system model

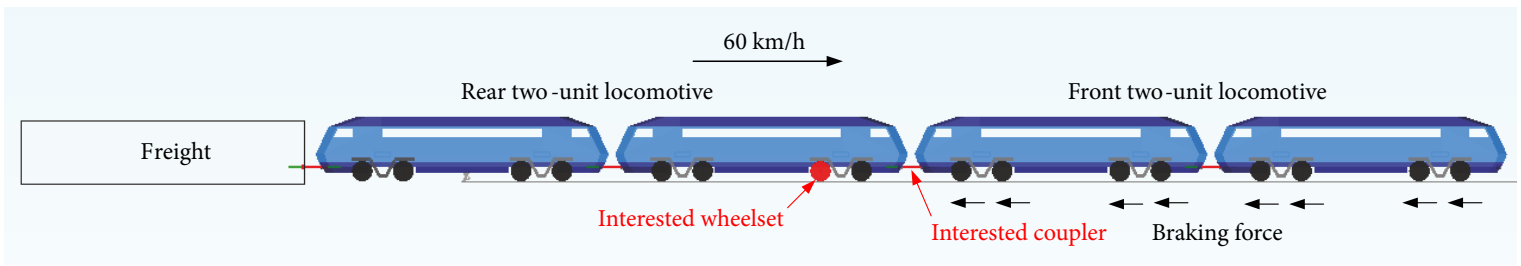

Figure 7. Braking operation in the model 
locomotive can be improved by increasing lateral stiffness of secondary suspensions. In detail, when $k \leq 300 \mathrm{kN} / \mathrm{m}$, both coupler and carbody yaw angles reach the maximum values. It should be pointed out that the locomotive destabilization occurs. The locomotive destabilization time for $k=300 \mathrm{kN} / \mathrm{m}$ is about $2.5 \mathrm{~s}$ later than that of $k=100 \mathrm{kN} / \mathrm{m}$. When $k \geq 400 \mathrm{kN} / \mathrm{m}$, locomotives keep stable, and the carbody and coupler yaw angles are less than the maximum values. The yaw behaviour of locomotive is in accordance with the wheelset lateral force and the derailment coefficient of locomotives, as shown in Figure 9. According to the UIC 518 (E) (2009), the safety value of wheelset lateral force is no more than $93 \mathrm{kN}$. For the case of $k \leq 300 \mathrm{kN} / \mathrm{m}$, the maximum wheelset lateral forces are around $140 \mathrm{kN}$ that is much larger than $93 \mathrm{kN}$. In this case, heavy-haul locomotives are likely to derail. It can be seen from the Figure $9 \mathrm{~b}$ that the derailment coefficient remains a high value when maximum yaw angles appear. For the case of $k \geq 400 \mathrm{kN} / \mathrm{m}$, the maximum wheelset lateral forces are 70 and $45 \mathrm{kN}$, respectively. It indicates that the locomotive is safe.

In order to improve heavy-haul locomotive stability during braking, choosing the right lateral stiffness of

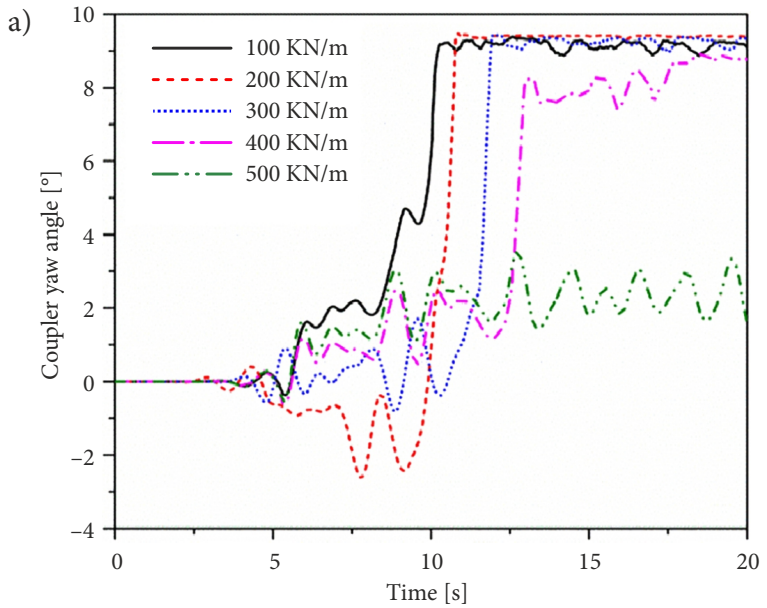

secondary suspensions should consider the coupler force and the friction coefficient of the coupler tail. When couplers keep stable, the couple can suffer the maximum compressive force under different lateral stiffness of secondary suspensions, as shown in Figure 10. In fact, the friction coefficient always remains at $0.15 \ldots 0.25$. For the front locomotive, the maximum coupler force is around $1000 \ldots 1500 \mathrm{kN}$. So, the increasing of the lateral stiffness of secondary suspensions is an effective way to improve the stability capacity of locomotives during braking. The value should be larger than $400 \mathrm{kN} / \mathrm{m}$.

\section{Field braking experiments}

\subsection{Test locomotives and coupler systems}

Three double-unit heavy-haul locomotives were used to conduct field braking experiments in order to understand the unstable process of locomotives and verify the dynamic model. The test locomotive is one of the main heavy-haul locomotives and widely adopted in Chinese heavy-haul railways. Its axle load and maximum operation speed are $25 \mathrm{t}$ and $120 \mathrm{~km} / \mathrm{h}$, respectively. Figure 11 shows the locomotive formation in the experiment.

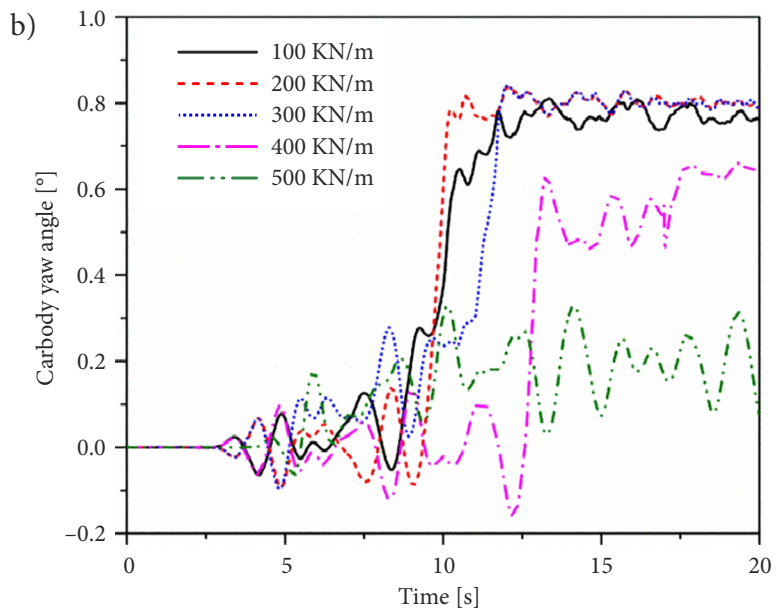

Figure 8 . The yaw behaviour: $\mathrm{a}$ - coupler yaw angle; $\mathrm{b}$ - carbody yaw angle
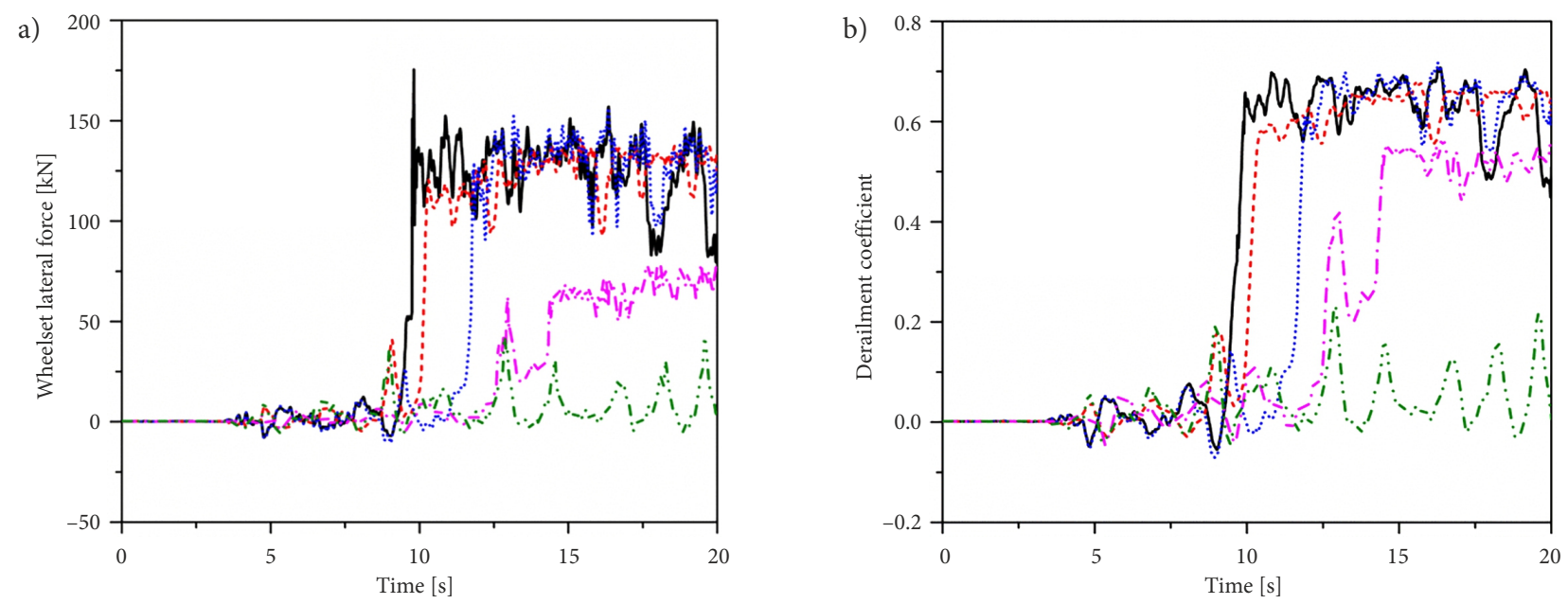

Figure 9. The running safety index: $a$ - wheelset lateral force; $b$ - derailment coefficient 


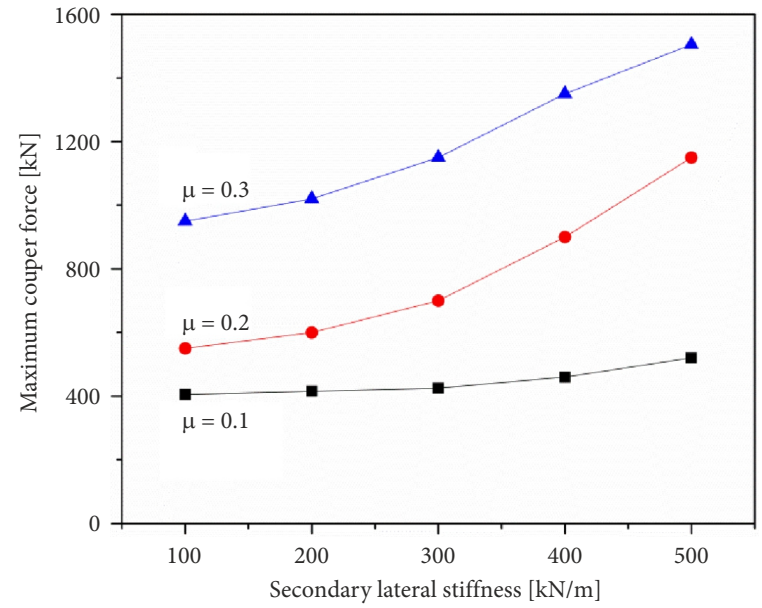

Figure 10. The maximum coupler compressive force

Test locomotives were connected by 13A/QKX100 coupler and draft gear systems. The friction coefficient is difficult to maintain in a high level because of the frequent braking, which leads to a large coupler yaw angle and great coupler lateral force. It has a significant effect on locomotive stability during braking.

In addition, the experiment line was a straight line. For the limitation of the test line, the maximum speed was limited to $60 \mathrm{~km} / \mathrm{h}$ in the experiment.

\subsection{Method of the field experiment}

Acceleration sensors and displacement sensors were installed on the test locomotives to detect the yaw behaviour and dynamic performance of heavy-haul locomotives. Acceleration sensors can obtain accelerations of carbody and bogies. Displacement sensors can measure dynamic dis-
Table 3. Sensors used in the running tests

\begin{tabular}{|l|l|}
\hline \multicolumn{1}{|c|}{ Sensors } & \multicolumn{1}{|c|}{ Measurement } \\
\hline S1, S2 & $\begin{array}{l}\text { Lateral displacement between the front coupler } \\
\text { and the carbody }\end{array}$ \\
\hline S3 & $\begin{array}{l}\text { Lateral displacement between the front bogie } \\
\text { and the carbody }\end{array}$ \\
\hline S4 & $\begin{array}{l}\text { Lateral displacement between the rear bogie } \\
\text { and the carbody }\end{array}$ \\
\hline S5, S6 & $\begin{array}{l}\text { Lateral displacement between the rear coupler } \\
\text { and the carbody }\end{array}$ \\
\hline A1 & $\begin{array}{l}\text { Accelerations of the carbody in vertical and } \\
\text { lateral directions }\end{array}$ \\
\hline A2 & $\begin{array}{l}\text { Accelerations of the axle box frame in vertical } \\
\text { and lateral directions }\end{array}$ \\
\hline A3 & $\begin{array}{l}\text { Accelerations of the bogie frame in vertical } \\
\text { and lateral directions }\end{array}$ \\
\hline F1 & Force of the front coupler \\
\hline F2 & Force of the rear coupler \\
\hline
\end{tabular}

placements of carbody and coupler in order to calculate the rotation angles of both carbody and coupler. Strain gauges are fixed on the couplers to detect the coupler compressive forces. Figure 12 and Table 3 illustrate the layout of the sensors employed in the running tests. The sampling frequency was $2000 \mathrm{~Hz}$ and data were obtained by Integrated Measurement and Control (IMC) devices.

\subsection{Procedure of the field experiment}

Firstly, all the test locomotives speeded up to $60 \mathrm{~km} / \mathrm{h}$. Then, the Locomotive- 1 started to brake and reached $100 \%$ electric braking. Locomotive- 2 conducted traction operation and reached $50 \%$ traction while Locomotive-3

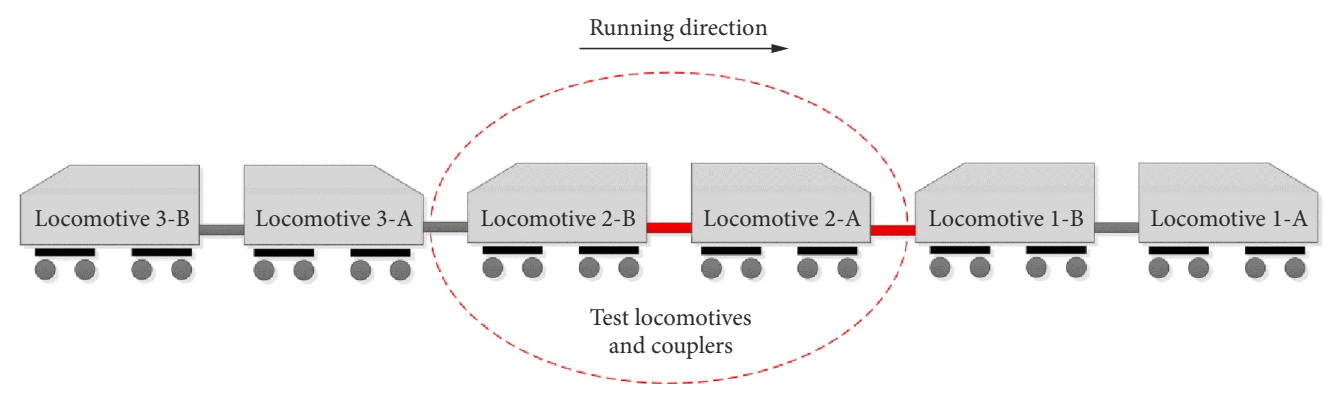

Figure 11. The locomotive formation in the experiment

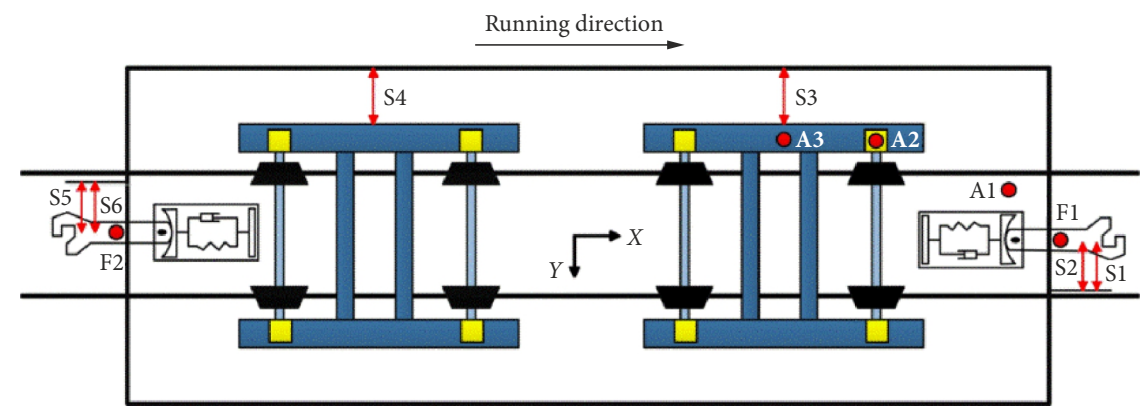

Figure 12. Layout of the sensors 
idled at the same time. In this situation, carbody of Locomotive-2 suffered the largest compressive forces. Its yaw behaviour and dynamic performance were interested targets in this paper. The lateral stiffness of secondary suspensions of locomotives was $130 \mathrm{kN} / \mathrm{m}$. In particular, the lateral stiffness equals the longitudinal stiffness because the secondary suspension of heavy-haul locomotive is cylindrical coil spring.

\section{Experiment-simulation comparison}

It is necessary to validate the dynamic simulation model of heavy-haul locomotives by comparing the experiment data with the simulation results. The simulation conditions are set to be consistent with the field braking test. It should be noted that Locomotive- 3 can be regarded as a freight vehicle since Locomotive- 3 idled during the braking test. As shown in Figure 7, Locomotive-3 was simplified as a single mass with only one DOF in the longitudinal direction in the simulation model in order to reduce computational effort. The train model is set to run at a speed $60 \mathrm{~km} / \mathrm{h}$ on

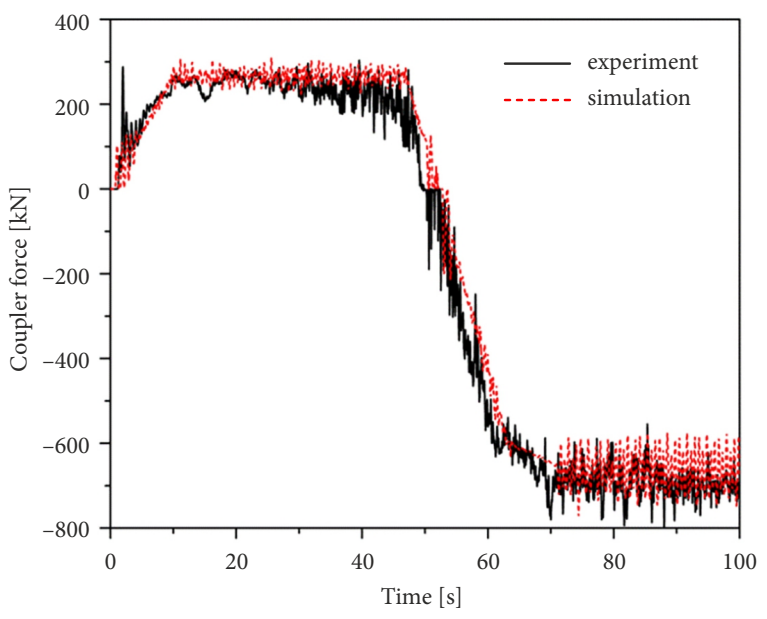

Figure 13. Coupler force of both the simulation and the experiment

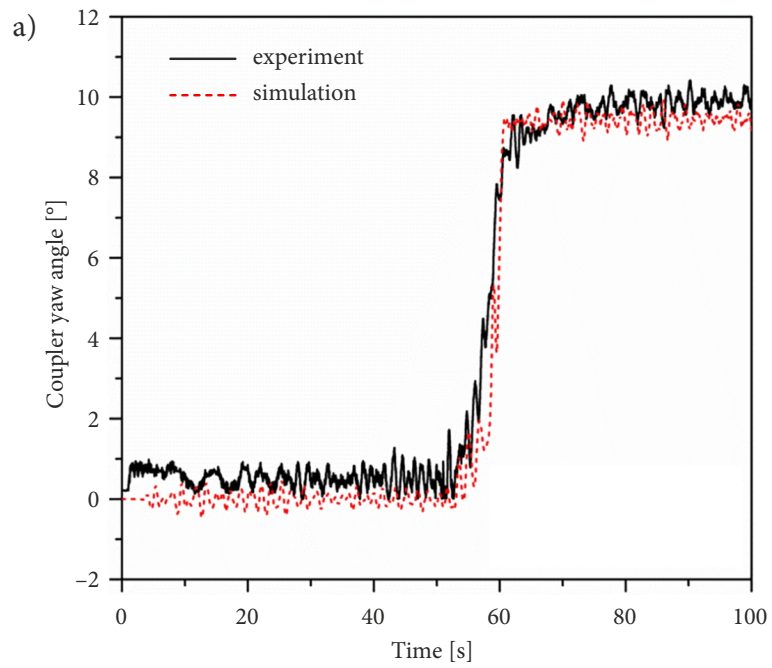

a straight track with FRA Class 5 track irregularities. The secondary lateral and longitudinal stiffness are $130 \mathrm{kN} / \mathrm{m}$. The friction coefficient of arc surface is set to be 0.2 . The maximum carbody yaw angle and coupler yaw angle are set to be 0.8 and $10^{\circ}$, respectively. Other dynamic and geometrical parameters are set to be the same with the parameters of test locomotives. The braking force is applied on per axle of the front double-unit locomotive, at the same time, its value depends on the measured coupler force in the field braking experiment. The total simulation time is $100 \mathrm{~s}$ and its calculation step is $0.005 \mathrm{~s}$.

The coupler force of the experiment and the simulation are shown in Figure 13. It is clear that the simulation coupler force is similar with that of the experiment. The braking operation starts at around $47 \mathrm{~s}$, and reaches the maximum braking force at around $61 \mathrm{~s}$. The maximum coupler force is around $750 \mathrm{kN}$. Figure 14 depicts the coupler and carbody yaw angles of both the experiment and the simulation. Both carbody and coupler yaw angles have a similar trend to the experiment ones, so the dynamic model can accurately reflect the yaw behaviour of heavy-haul locomotive during braking. During $47 \ldots .57 \mathrm{~s}$, the locomotive keep stable and its yaw angle remains at a small range. The instability appears at around $58 \mathrm{~s}$. Then, the locomotive reaches its maximum yaw angle in three seconds. Finally, the rigid contact between the carbody and secondary lateral stopper occurs, which prevents the further yaw behaviour of heavy-haul locomotive. The only difference is that the maximum coupler yaw angle of the simulation is little smaller than that of the experiment. The reason is the clearance between the coupler yoke and the carbody. The above comparative results can indicate that the established simulation model can accurately simulate the real braking situation and reflect the yaw behaviour and dynamic performance of the heavy-haul locomotive during braking.

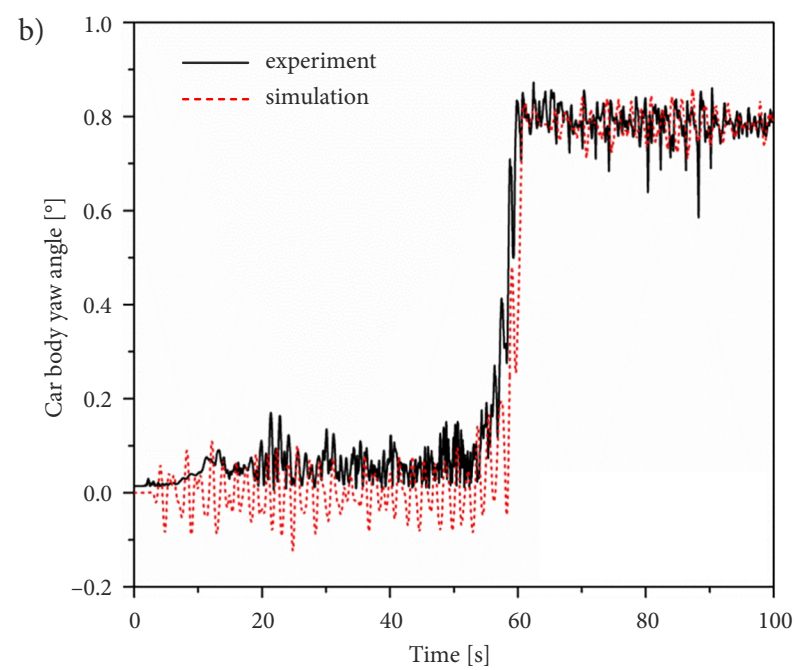

Figure 14. Comparison of the experiment and the simulation: a - coupler yaw angle; b - carbody yaw angle 


\section{Original-improved locomotives comparison}

According to the simulation results, the lateral stiffness of secondary suspensions of the test locomotives was increased to around $400 \mathrm{kN} / \mathrm{m}$. The original and improved locomotives were used to conduct the field braking experiments, respectively. Other experiment conditions are the same.

As shown in Figure 15, the coupler forces of two experiments have similar variation and value. Therefore, these braking situations can be considered as the same. Due to the operation of the driver, the braking time of the improved experiment is later $3 \mathrm{~s}$ than that of the original experiment. Figure 16 illustrates the yaw behaviour of the test locomotives. It is clear that the increasing lateral stiffness of secondary suspensions has an important effect on

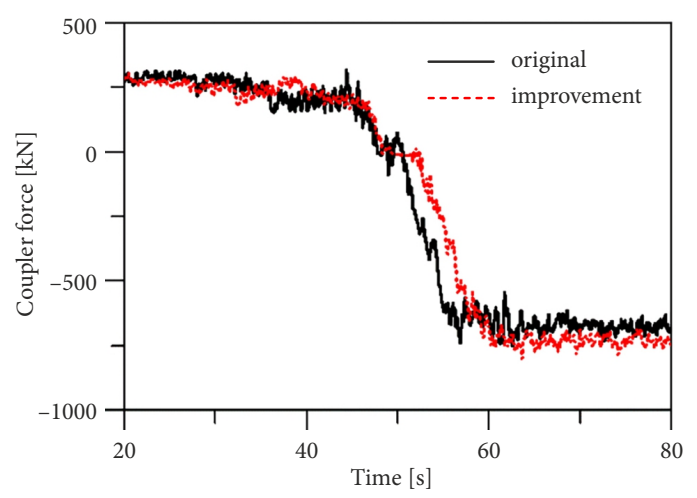

Figure 15. The coupler forces in the tests

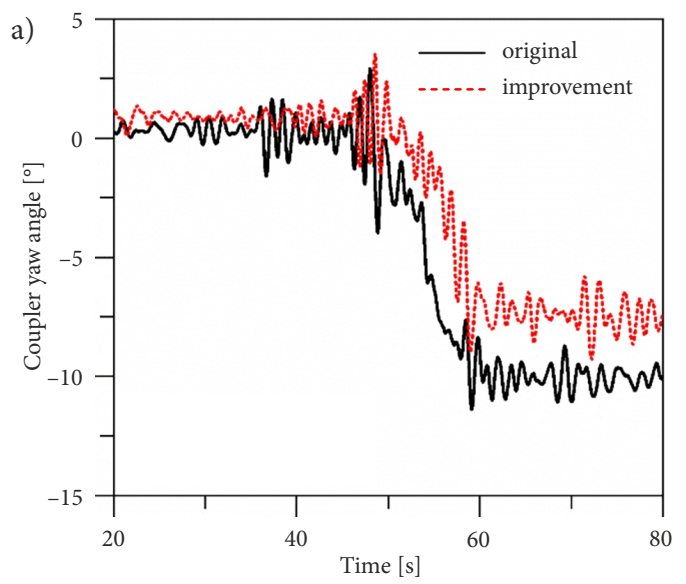

decreasing the coupler and carbody yaw angles. In detail, the coupler yaw angle was decreased by $31.8 \%$ as well as the carbody yaw angle was decreased by $29.5 \%$. In particular, the yaw angle of the improved locomotive is smaller than that of the original locomotives during $20 \ldots 40 \mathrm{~s}$. Since the coupler yaw angles of the original locomotives reaches the maximum value around $0.8^{\circ}$, the rigid contact between the carbody and the yaw stopper occurs, as shown in Figure 17a. On the contrary, there is not abrasion on the yaw stopper of the improved locomotives, as shown in Figure 17b. Accordingly, the stability capacity of the heavy-haul locomotives increases with the increasing of the lateral stiffness of secondary suspensions.

Figure 18 depicts the dynamic responses of the test locomotive. It is obvious that the lateral stiffness of secondary suspensions has little influence on dynamic responses of the heavy-haul locomotive, except for the lateral acceleration of the carbody. The lateral acceleration of the carbody becomes greater as lateral stiffness of secondary suspensions is increased, especially during locomotive braking. As shown in Figure 19, the main frequency of the original locomotive is $0.5 \ldots 1 \mathrm{~Hz}$ as well as the main frequency of the improved locomotive is $1 \ldots 2 \mathrm{~Hz}$. Besides, high frequency variation is increased, especially $10 \ldots 12.5 \mathrm{~Hz}$. Therefore, the riding comfort will be decreased. Sperling index of the improved locomotive is 2.83 during locomotive braking, which is larger than that of the original locomotive, 2.49. According to the UIC 518 (E) (2009), the riding comfort of the improved locomotive is qualified.

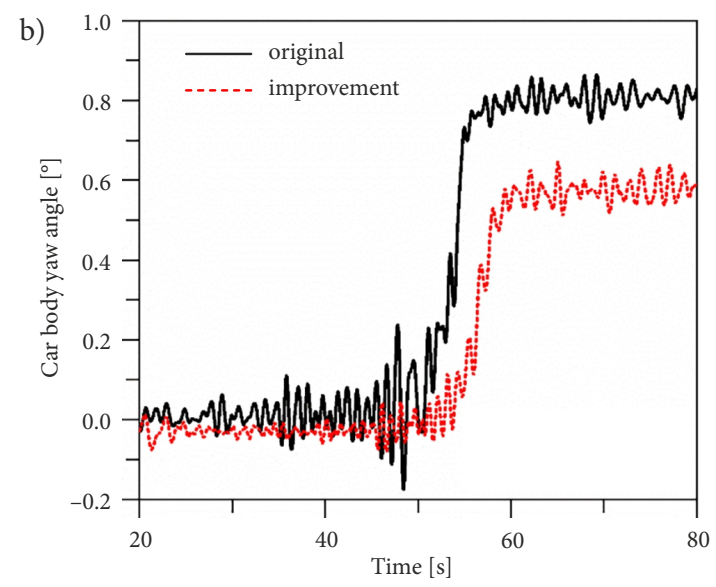

Figure 16. Comparison of the experiments: a - coupler yaw angle; b - carbody yaw angle
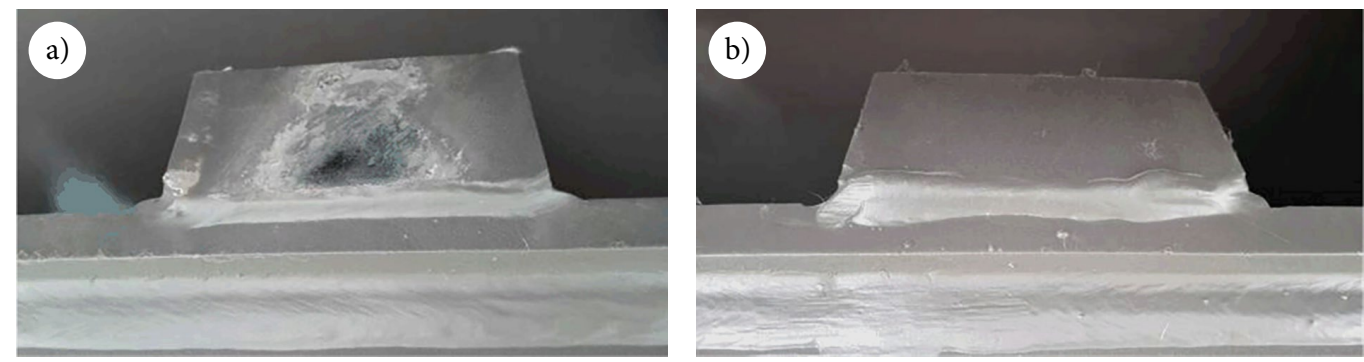

Figure 17. The contact conditions of the yaw stoppers: $\mathrm{a}$ - original locomotive; $\mathrm{b}$ - improved locomotive 
a)

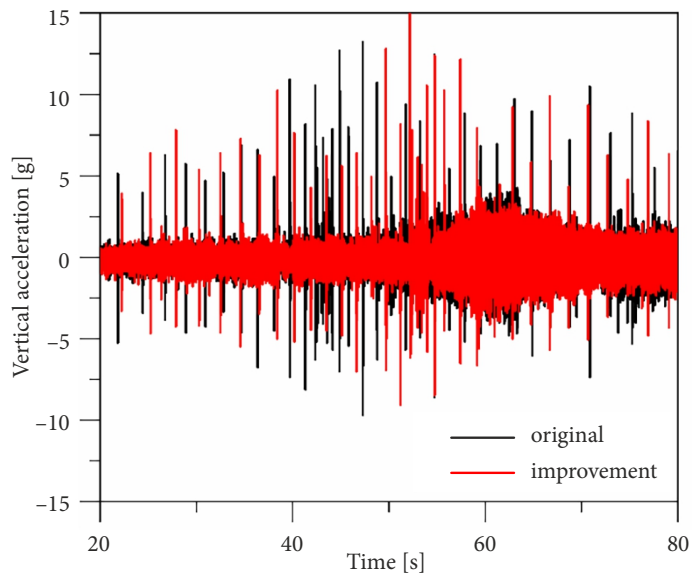

b)

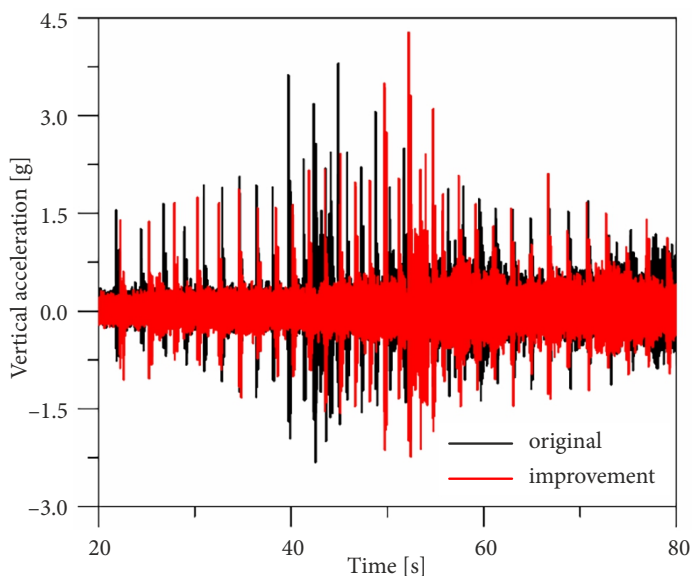

c)

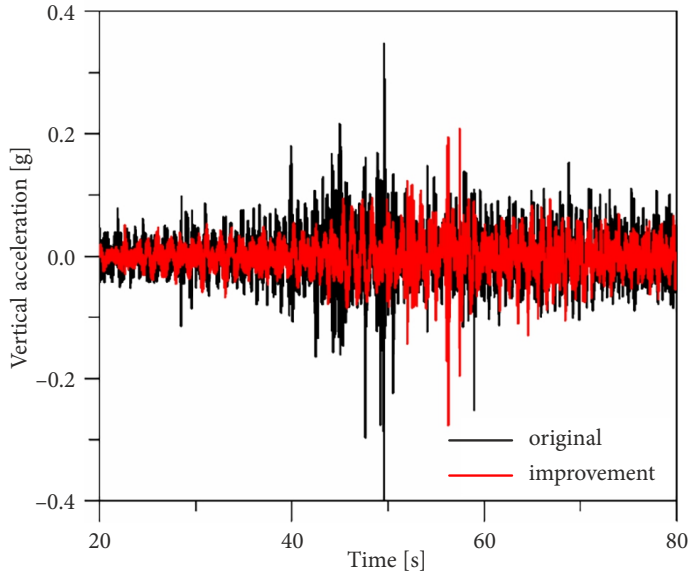

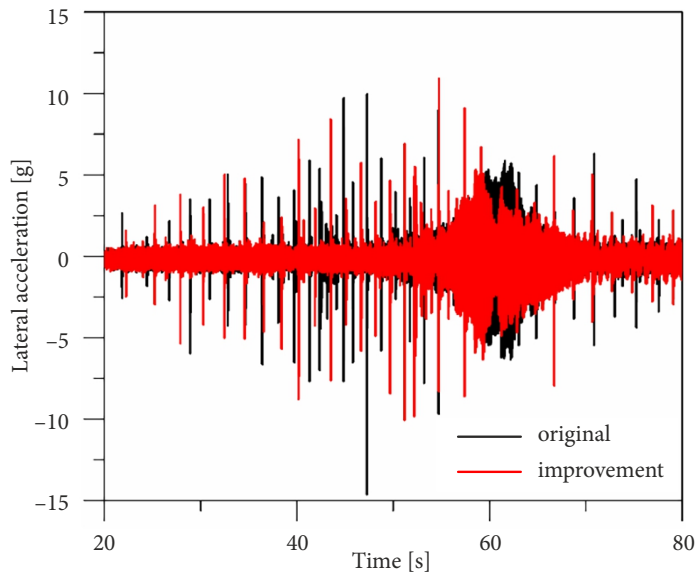
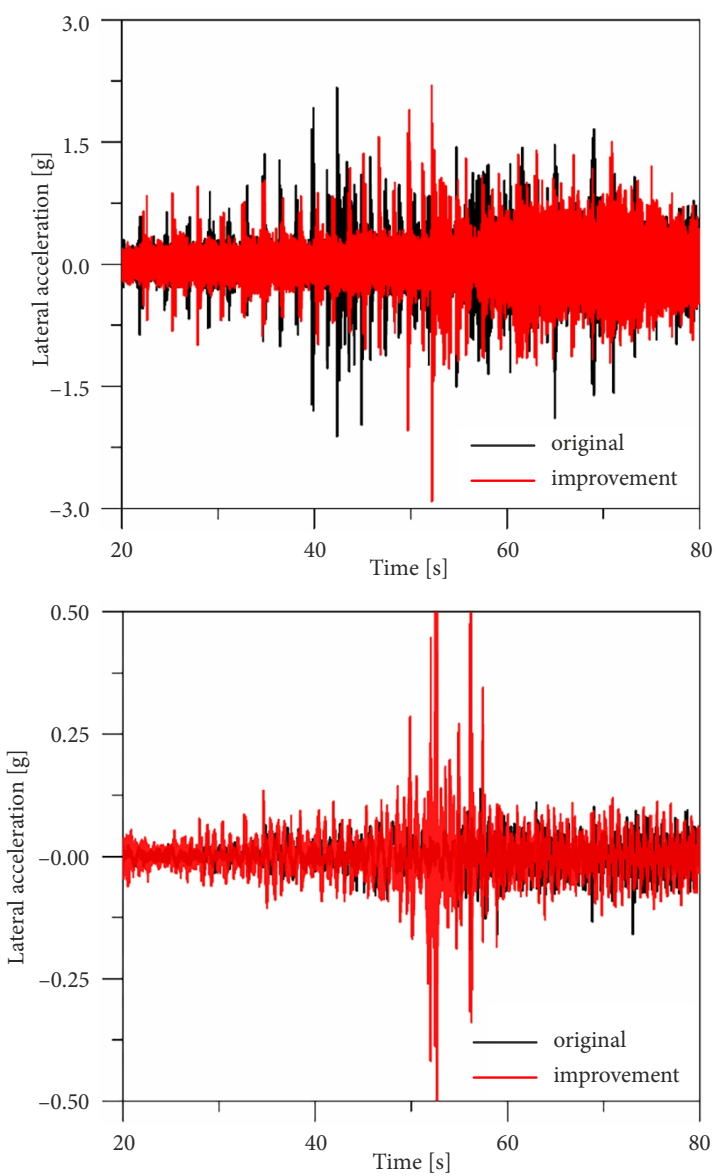

Figure 18. The acceleration of the test locomotive: $\mathrm{a}$ - axle box; $\mathrm{b}$ - bogie frame; $\mathrm{c}$ - carbody

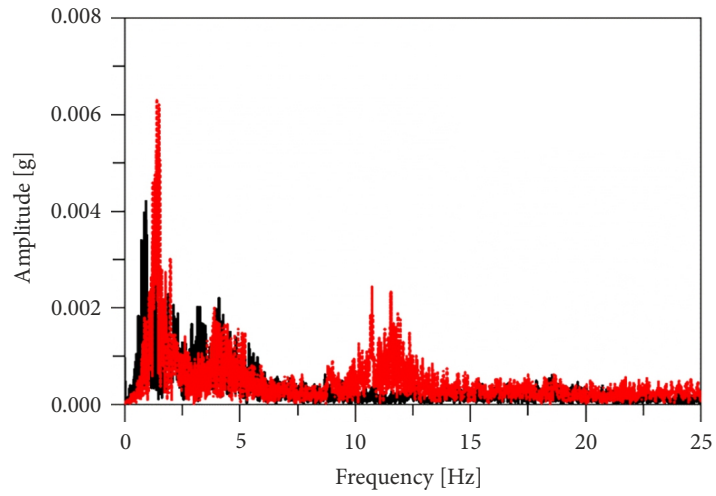

Figure 19. The amplitude-frequency analysis of the lateral acceleration of the carbody 
Table 4 lists the maximum value of the experiment results and the simulation results under the same braking conditions. The maximum value of the simulation is close to that of the experiment and proves the accuracy of the simulation model. In particular, the maximum coupler yaw of the simulation $9.88^{\circ}$ is less than that of experiment because it is set as $10^{\circ}$ in the model.

Table 4. The results of the experiments and the simulation

\begin{tabular}{|c|c|c|c|c|}
\hline \multirow[b]{2}{*}{ Item } & \multicolumn{2}{|c|}{ Experiment } & \multicolumn{2}{|c|}{ Simulation } \\
\hline & original & $\begin{array}{l}\text { improve- } \\
\text { ment }\end{array}$ & original & $\begin{array}{l}\text { improve- } \\
\text { ment }\end{array}$ \\
\hline \multicolumn{5}{|c|}{ Compressive force $[\mathrm{kN}]$} \\
\hline Front coupler & 750 & 790 & 750 & 790 \\
\hline Rear coupler & 389 & 369 & 390 & 370 \\
\hline \multicolumn{5}{|c|}{ Yaw angle $\left[^{\circ}\right]$} \\
\hline Front coupler & 11.22 & 8.11 & 9.88 & 8.21 \\
\hline Rear coupler & 10.23 & 6.25 & 9.82 & 6.15 \\
\hline Front carbody & 0.86 & 0.64 & 0.82 & 0.61 \\
\hline Rear carbody & 0.56 & 0.35 & 0.59 & 0.37 \\
\hline \multicolumn{5}{|c|}{ Sperling index } \\
\hline $\begin{array}{l}\text { Lateral direction } \\
\text { during traction }\end{array}$ & 1.67 & 2.06 & 1.72 & 2.11 \\
\hline $\begin{array}{l}\text { Lateral direction } \\
\text { during braking }\end{array}$ & 2.49 & 2.83 & 2.45 & 2.85 \\
\hline $\begin{array}{l}\text { Vertical direction } \\
\text { during traction }\end{array}$ & 1.95 & 1.75 & 1.85 & 1.80 \\
\hline $\begin{array}{l}\text { Vertical direction } \\
\text { during braking }\end{array}$ & 2.30 & 2.34 & 2.28 & 2.30 \\
\hline
\end{tabular}

\section{Conclusions}

In order to improve the stability capacity and the running safety of heavy-haul locomotives, the effect of the lateral stiffness of secondary suspensions was investigated by both the simulation model and the field braking experiments. The following conclusions are drawn from the presented results:

1) for the original locomotive, the carbody and coupler yaw angles can reach the maximum value when the maximum coupler force is $750 \mathrm{kN}$. The phenomenon has a significant influence on the running safety of the heavy-haul locomotive;

2) the established dynamic model of the locomotive can accurately simulate the yaw behaviour and dynamic performance of heavy-haul locomotives under severe compressive forces;

3) according to the simulation results, increasing the lateral stiffness of secondary suspensions can reduce the locomotive's yaw angle and improve the stability capacity of heavy-haul locomotives during braking, especially when coupler force is less than $1000 \mathrm{kN}$;

4) for the improved locomotive, the coupler and carbody yaw angles decrease by 31.8 and $29.5 \%$, respectively. However, the lateral vibration of the carbody is enhanced so that the riding comfort decreases.
Since all conclusions are based on the straight line, the results cannot reflect the yaw behaviour and dynamic responses of heavy-haul locomotives on the curve line. In the future work, the dynamic model and field experiments are expected to be developed and conducted on the curve line to study more effective limitation measurements.

\section{Funding}

This work was supported by the National Basic Research Program of China under Grant No 51825504, the National Basic Research Program of China under Grant No 51405400, and the Program of Introducing Talents of Discipline to Universities (111 Project) under Grant No B16041.

\section{Acknowledgments}

The authors would like to thank the State Key Laboratory of Traction Power (Southwest Jiaotong University, China) for providing office, equipment, and materials to this project, and CRRC Datong Co., Ltd. for the cooperation and support.

We thank Jiangtian Zhang and Hongrui Qi for their assistance in the test.

\section{References}

Belforte, P.; Cheli, F.; Diana, G.; Melzi, S. 2008. Numerical and experimental approach for the evaluation of severe longitudinal dynamics of heavy freight trains, Vehicle System Dynamics: International Journal of Vehicle Mechanics and Mobility 46: 937-955. https://doi.org/10.1080/00423110802037180

Chen, Z.; Zhai, W.; Wang, K. 2017. A locomotive-track coupled vertical dynamics model with gear transmissions, Vehicle System Dynamics: International Journal of Vehicle Mechanics and Mobility 55(2): 244-267.

https://doi.org/10.1080/00423114.2016.1254260

Cole, C.; McClanachan, M.; Spiryagin, M.; Sun, Y. Q. 2012.Wagon instability in long trains, Vehicle System Dynamics: International Journal of Vehicle Mechanics and Mobility 50: 303-317. https://doi.org/10.1080/00423114.2012.659742

Cole, C.; Sun, Y. Q. 2006. Simulated comparisons of wagon coupler systems in heavy-haul trains, Proceedings of the Institution of Mechanical Engineers, Part F: Journal of Rail and Rapid Transit 220(3): 247-256. https://doi.org/10.1243/09544097JRRT35

Geike, T. 2007. Understanding high coupler forces at metro vehicles, Vehicle System Dynamics: International Journal of Vehicle Mechanics and Mobility 45(4): 389-396. https://doi.org/10.1080/00423110701215085

Guo, L.; Wang, K.; Lin, J.; Zhang, B.; Chen, Z.; Song, X.; Du, G. 2016. Study of the post-derailment safety measures on lowspeed derailment tests, Vehicle System Dynamics: International Journal of Vehicle Mechanics and Mobility 54(7): 943-962. https://doi.org/10.1080/00423114.2016.1175646

Ma, W.; Luo, S.; Song, R. 2012. Coupler dynamic performance analysis of heavy-haul locomotives, Vehicle System Dynamics: International Journal of Vehicle Mechanics and Mobility 50(9): 1435-1452. https://doi.org/10.1080/00423114.2012.667134

Nasr, A.; Mohammadi, S. 2010. The effects of train brake delay time on in-train forces, Proceedings of the Institution of Mechanical Engineers, Part F: Journal of Rail and Rapid Transit 224(6): 523-534. https://doi.org/10.1243/09544097JRRT306 
Simson, S. A.; Cole, C. 2008. Simulation of curving at low speed under high traction for passive steering hauling locomotives, Vehicle System Dynamics: International Journal of Vehicle Mechanics and Mobility 46(12): 1107-1121. https://doi.org/10.1080/00423110701883163

UIC 518 (E). 2009. Testing and Approval of Railway Vehicles from the Point of View of their Dynamic Behaviour - Safety - Track Fatigue - Ride Quality.

Wang, K.; Liu, P.; Zhai, W.; Huang, C.; Chen, Z.; Gao J. 2015. Wheel/rail dynamic interaction due to excitation of rail corrugation in high-speed railway, Science China Technological Sciences 58(2): 226-235. https://doi.org/10.1007/s11431-014-5633-y

Wang, K.; Zhai, W. 2009. Dynamic interaction between heavy locomotive and track under longitudinal force of coupler, Journal of Southwest Jiaotong University 44(1): 7-12. (in Chinese).

Wang, K.; Zhai, W.; Lv, K.; Chen, Z. 2016a. Numerical investigation on wheel-rail dynamic vibration excited by rail spalling in high-speed railway, Shock and Vibration 2016: 9108780. https://doi.org/10.1155/2016/9108780

Wang, K.; Zhang, R.; Chen, Z.; Shi, Z. 2016b. Effect of coupler position errors on dynamic performance of heavy-haul locomotive, Journal of Southwest Jiaotong University 51(6): 1041-1046. (in Chinese).

Wu, Q.; Cole, C.; Luo, S.; Spiryagin, M. 2014. A review of dynamics modelling of friction draft gear, Vehicle System Dynamics: International Journal of Vehicle Mechanics and Mobility 52(6): 733-758. https://doi.org/10.1080/00423114.2014.894199

Wu, Q.; Luo, S.-H.; Wei, C.-F.; Ma, W.-H. 2012. Dynamics simulation models of coupler systems for freight locomotive, Journal of Traffic and Transportation Engineering 12(3): 37-43.

Xu, Z.; Wu, Q.; Luo, S.; Ma, W.; Dong, X. 2014. Stabilizing mechanism and running behavior of couplers on heavy-haul trains, Chinese Journal of Mechanical Engineering 27(6): 1211-1218. https://doi.org/10.3901/CJME.2014.0905.146

Yao, Y.; Liu, X.; Zhang, H.; Luo, S. 2014. The stability and mechanical characteristics of heavy-haul couplers with restoring bumpstop, Vehicle System Dynamics: International Journal of Vehicle Mechanics and Mobility 52(1): 26-44. https://doi.org/10.1080/00423114.2013.849352

Yao, Y.; Zhang, X.-X.; Zhang, H.-J.; Luo, S.-H. 2013. The stability mechanism and its application to heavy-haul couplers with arc surface contact, Vehicle System Dynamics: International Journal of Vehicle Mechanics and Mobility 51(9): 1324-1341. https://doi.org/10.1080/00423114.2013.801500

Zhai, W. 2020. Vehicle-Track Coupled Dynamics: Theory and Applications. Springer. $417 \mathrm{p}$. https://doi.org/10.1007/978-981-32-9283-3

Zhai, W.; Liu, P.; Lin, J.; Wang, K. 2015. Experimental investigation on vibration behaviour of a CRH train at speed of $350 \mathrm{~km} / \mathrm{h}$, International Journal of Rail Transportation 3(1): 1-16. https://doi.org/10.1080/23248378.2014.992819

Zhang, Z.; Li, G.; Chu, G.; Zu, H.; Kennedy, D. 2015. Compressed stability analysis of the coupler and buffer system of heavyhaul locomotives, Vehicle System Dynamics: International Journal of Vehicle Mechanics and Mobility 53(6): 833-855. https://doi.org/10.1080/00423114.2015.1023318 